\title{
TASK 2.5.4 DEVELOPMENT OF AN ENERGY SAVINGS CALCULATOR
}

\author{
William (Bill) Miller, Ph.D. \\ Oak Ridge National Laboratory \\ Research Engineer \\ Building Envelope Program
}

\section{Yu Joe Huang \\ President}

White Box Technologies, Inc
Joshua New, Ph.D.

Oak Ridge National Laboratory

Computer Science Specialist

Building Envelope Program

Ender Erdem, Ph.D.

Programmer DOE-2.1E Specialist

White Box Technologies, Inc

\author{
Andre Desjarlais \\ Oak Ridge National Laboratory \\ Group Leader \\ Building Envelope Program \\ Ronnen Levinson, Ph.D. \\ Lawrence Berkeley National \\ Laboratory \\ Leader, Heat Island Group
}

\section{ABSTRACT}

California's major energy utilities and the California Energy Commission (CEC) are seeking to allocate capital that yields the greatest return on investment for energy infrastructure that meets any part of the need for reliable supplies of energy. The utilities are keenly interested in knowing the amount of electrical energy savings that would occur if cool roof color materials are adopted in the building market. To meet this need the Oak Ridge National Laboratory and the Lawrence Berkeley National Laboratory (LBNL) have been collaborating on a Public Interest Energy Research (PIER) project to develop an industry-consensus energy-savings calculator. The task was coordinated with an ongoing effort supported by the DOE to develop one calculator to achieve both the DOE and the EPA objectives for deployment of cool roof products. Recent emphasis on domestic building energy use has made the work a top priority by the Department of Energy's (DOE) Building Technologies Program.

The Roof Savings Calculator (RSC) tool is designed to help building owners, manufacturers, distributors, contractors and practitioners easily run complex simulations. The latest web technologies and usability design were employed to provide an easy input interface to an annual simulation of hour-by-hour, whole-building performance using the world-class simulation tools DOE-2.1E and AtticSim. Building defaults were assigned based on the best available statistical evidence and can provide energy and cost savings after the user selects nothing more than the building location.

A key goal for the tool is to promote the energy benefits of cool color tile, metal and asphalt shingle roof products and other energy saving systems. The RSC tool focuses on applications for the roof and attic; however, the code conducts a whole building simulation that puts the energy and heat flows of the roof and attic into the perspective of the whole house. An annual simulation runs in about $30 \mathrm{sec}$.

In addition to cool reflective roofs, the RSC tool will simulate high- medium- and low-slope roofs, and has a custom selection for the user whose house has a unique inclination. There is an option for above sheathing ventilation, which is prevalent in tile and stone-coated metal roof assemblies. The tool also accommodates the effects of radiant barriers and low-emittance surfaces in the inclined air space above the sheathing. The practitioner can select to have air-conditioning ducts either in the conditioned space 
or in the attic. If in the attic, the user can select one of three air leakage options. Option 1 is an inspected duct having 4\% leakage and code level of duct insulation; option 2 is a poorly insulated duct having 14\% air leakage; and option 3 is a custom leakage rate specified by the user. The practitioner can setup multiple layers of ceiling insulation.

AtticSim is benchmarked against the field data acquired for Ft. Irwin located near Barstow, CA, first as a standalone simulation program and then again integrated within the DOE-2.1E program. The standalone benchmark was very useful to determining how well AtticSim replicates the building physics of an attic. The coupled benchmark was useful to verify that the DOE-2.1E/AtticSim code is modeling correctly the dynamic relationship between the attic and the occupied space below, as well as the interactions between the attic and the HVAC system, in particular when the ducts are located in the attic.

\section{DOE-2.1E}

$D O E-2.1 E[1][2]$ is a whole-building energy simulation program that was originally developed by Lawrence Berkeley National Laboratory in the early 1980's (Version 2.1A), with continued development through 1993 (Ver. 2.1B through 2.1E) [3]. $D O E-2.1 E$ is the most current version of $D O E-2$ that is in the public domain, although there are later efforts and user-interfaces developed by private companies. Counting all its versions and user interfaces, $D O E-2$ is by far the most widely used building energy simulation program in the world today, and has been the basis of most performance-based building energy standards in the U.S. and at least ten other countries, as well as being used for voluntary "Green Building” rating systems such as the US Green Building Council's Leadership in Energy and Environmental Design (LEED).

$D O E-2$ itself is an engineering program, with a text-based input and output procedure. The program takes as input a description of the physical building and its space conditioning system, its internal conditions, e.g., schedules for occupancy and lighting, and operations, e.g., thermostat schedules, and the hourly weather conditions, e.g., temperature, humidity, wind speed, and solar radiation, and produces as output the energy consumption, as well as the indoor conditions, of the building. Using the program is difficult because it requires in-depth knowledge both of how DOE-2 works and how buildings are constructed and operated. Although there are numerous papers attesting to the fundamental soundness of the $D O E-2$ program, the fact remains that a computer model is only as good as are the inputs. The multiplicity of inputs can cause confounding results.

DOE-2 operates on an hourly time-step, and uses response factors to model the dynamic heat flows through the building envelope. At the zone level, DOE-2 uses weighting factors (also called zone response factors) to model the dynamic response of the space, taking into account its thermal mass or capacitance, heat loss through radiation and or convection. DOE-2 is made up of two programs, an input processing program called doebdl and a simulation program called doesim, which is composed of four separate modules called sequentially by $D O E-2.1 \mathrm{E}$. 


\section{Module 1. Loads}

The LOADS module simulates the heat flows in and out of the building and calculates the net balance at a fixed reference temperature, negative being interpreted as a heating load and positive as a cooling load.

\section{Module 2. System}

The SYSTEMS module takes the results from LOADS, simulates the operation of the HVAC system, and derives the actual zone temperatures, amount of heating and cooling provided by the system, and the energy consumed.

\section{Module 3. Plant}

If the building has a central plant, the heating and cooling demands from SYSTEMS are passed to the PLANT module that simulates the energy consumed by the plant to meet the SYSTEMS demands

\section{Module 4. Economics}

The ECONOMICS module computes energy costs and is not used in this application.

Although DOE stopped all support for DOE-2 in 1999, White Box Technologies and others have continued to maintain and even add features to $D O E-2.1 E$. For example, Huang [4] added an improved foundation model to the code at the request of the California Energy Commission (CEC). Most recently, LBNL approved making DOE2.1E open source code and White Box technologies announced the creation of an Open Source Center for Building Simulations to maintain the DOE-2.1E software for the community of building scientists and practitioners.

\section{Building Models}

For the Web-based Roofing Calculator, four template files have been created for four building input types - residential, medium-sized office, warehouse, and big box retail store. The residential file is adapted from the template file developed by Huang [5] for the RESFEN program, a similar easy-to-use program for calculating window energy performance using $D O E-2$ as the simulation engine. The three commercial files are adapted from a set of commercial building prototypes first developed in 1990 [5] that later served as the basis for DOE's commercial building benchmark models [6].

These are called template files because they contain numerous macros, a feature available in $D O E$-2 since the early 1990s that allow the file to be altered based on highlevel user inputs set in the Graphical User Interface (GUI). These high-level inputs include building location, vintage, floor area, number of floors, window-to-floor (residential) or window-to-wall (commercial) ratio, and HVAC equipment. As befitting a Roofing Calculator, the user inputs are much more specific for the attic/roof assembly, including the roof construction, cover material, pitch, solar reflectance, and thermal emittance, inclusion of radiant barrier, duct location and characteristics, and ceiling Rvalue. For a complete list of the user inputs, please refer to later section on Web Deployment. 
Once these user inputs have been set, the macro statements allow the template file to be modified accordingly.

\section{ATTICSIM}

AtticSim is a computer tool for predicting the thermal performance of residential attics. The code is publicly available as an ASTM protocol [7]. It mathematically describes the conduction through the gables, eaves, roof deck and ceiling; the convection at the exterior and interior surfaces; the radiosity heat exchange between surfaces within the attic enclosure; the heat transfer to the ventilation air stream; and the latent heat effects due to sorption and desorption of moisture at the wood surfaces. Solar reflectance, thermal emittance and water vapor permeance of the sundry surfaces are input. The model can account for different insulation R-values and/or radiant barriers attached to the various attic surfaces. It also has an algorithm for predicting the effect of air-conditioning ducts placed in the attic, Petrie [8].

Typical construction places ductwork within the attic, which can literally triple the loads for the attic assembly for moderately leaky ducts Petrie [8] and Parker, Fairey, and Gu [9]. Petrie [10] validated the duct algorithm in ASTM C 1340 against experimental data for an attic assembly tested first without and then with a radiant barrier attached to the underside of the roof deck. Validations showed the duct algorithm predicted the duct air change (inlet-to-outlet of the supply duct) within $\pm 0.3^{\circ} \mathrm{F}\left( \pm 0.2^{\circ} \mathrm{C}\right)$ over all tests housing an insulated duct system.

AtticSim was the subject of an extensive field validation conducted by Ober and Wilkes for ASHRAE [11], which provides mathematical documentation of the code and validation results for low-slope and steep-slope field data collected from seven different field sites. AtticSim can simulate a flat roof system as documented and validated in ASHRAE RP 717 (see pg 8-27 and pg 12-2 Joy field data). The code was later validated by Miller [12] for steep-slope asphalt shingle and stone-coated metal roofs. Miller [13] also benchmarked the code against clay and concrete tile and painted metal roof and attic assemblies that exhibit above-sheathing ventilation. Miller [13] was able to predict the heat transfer crossing the air space.

The heat flows at the attic's ceiling, roof section's, gables and eaves are calculated using the thermal response factor technique by Mitalas and Stephenson [14], which requires the thermal conductivity, specific heat, density and thickness of each attic section for calculating conduction transfer functions. DOE-2.1E uses a similar technique of response factors (RF) to calculate heat flows through the building envelope, but uses weighting factors (WF) to model the heat gain.

The compatibility of the two sets of procedures and their setup for computing parallel path heat flows was a key hurdle for making AtticSim work seamlessly within the "Systems" framework of the DOE-2.1E program. White Box Technology made a comparison of the response factors generated by DOE-2 to those used by AtticSim. It was found that the two routines computed about the same values the only difference is that DOE-2 starts using the common ratio earlier than does that used by AtticSim. Table 1 displays results for the west facing gable roof, Table 1 . The ratio of two consecutive response factors is termed the common ratio and it becomes constant after a sufficient number of terms. 
As stated AtticSim is an ASTM protocol [7] and is publicly available. It has been extensively peered reviewed and benchmarked against field data, and therefore was an excellent candidate for use with the whole building model. DOE-2.1E does not adequately describe the radiation exchanges occurring in attics. AtticSim does not predict whole building performance. Combined, the two tools would offer a powerful feature that will be benchmarked against field data for CA demonstration homes being collected for the CEC.

Table 1. Sample Output from DOE-2.1E and AtticSim for the conduction transfer functions computed through the insulation path in the gable end of an attic.

\begin{tabular}{|c|c|c|c|}
\hline Attic Surface & \multicolumn{3}{|c|}{ DOE2.1E Response Factors } \\
\hline \multicolumn{4}{|l|}{ West_facing_gable_insulation_path } \\
\hline 0 & 0.0659029186 & 0.0304230750 & 0.0659029186 \\
\hline 1 & -0.0236259736 & 0.0117719891 & -0.0236259736 \\
\hline 2 & -0.0000408221 & 0.0000408221 & -0.0000408221 \\
\hline 3 & -0.0000001163 & 0.0000001163 & -0.0000001163 \\
\hline COMMON RATIO & 0.0028485756 & & \\
\hline Attic Surface & \multicolumn{3}{|c|}{ AtticSim Response Factors } \\
\hline \multicolumn{4}{|l|}{ West_facing_gable_insulation_path } \\
\hline 0 & 0.0659029161 & 0.0304230732 & 0.0659029161 \\
\hline 1 & -0.0236259750 & 0.0117719903 & -0.0236259750 \\
\hline 2 & -0.0000408222 & 0.0000408222 & -0.0000408222 \\
\hline 3 & -0.0000001163 & 0.0000001163 & -0.0000001163 \\
\hline COMMON RATIO & 0.0028485769 & & \\
\hline & \multicolumn{3}{|c|}{ Differences between DOE2.1E and Atticsim } \\
\hline 0 & -0.0000000025 & -0.0000000018 & -0.0000000025 \\
\hline 1 & -0.0000000014 & 0.0000000012 & -0.0000000014 \\
\hline 2 & -0.0000000001 & 0.0000000001 & -0.0000000001 \\
\hline 3 & 0.0000000000 & 0.0000000000 & 0.0000000000 \\
\hline 4 & 0.0000000013 & & \\
\hline
\end{tabular}

\section{Linkage to DOE-2.1E}

In the linkage to DOE-2.1E, AtticSim has been converted to a subroutine that is called in the SYSTEMS module, in effect replacing the TEMDEV subroutine that solves for the zone temperature and calculates the heat gain or extraction provided by the HVAC system. As SYSTEMS loops through the zones, it starts first with the attic, where it will invoke AtticSim, and pass to it inputs for the ambient conditions, thermal properties, i.e., response factors, of the surfaces, as well as temperature of the space below and the ontime of the HVAC system from the previous time step. AtticSim then returns to doesim the attic temperature, the heat flow through the ceiling, and the heat gain or loss to the ducts, which are used by doesim to solve for the temperature of the zone below, the heat addition or extraction and finally energy consumption of the HVAC system.

To affect this linkage, numerous changes were also necessary to the input processing doebdl program in order to pass the input data from the building model described in DOE-2's Building Description Language (BDL) to AtticSim. Some 20 new 
keywords have been added, in addition to the "data mining” of the existing $D O E-2$ inputs.

\section{WEB DEPLOYMENT}

An important objective identified early in development was to maximize the impact of this Public Interest Energy Research (PIER) project by providing a publicly accessible website for comparative simulations of traditional and energy-saving roofing options. This web portal is designed to serve as an industry-consensus roof savings calculator for commercial and residential buildings using whole-building energy simulations (Fig. 1); the managers for the DOE and EPA calculators [15][16] have agreed to take down their calculators prior to full deployment of the Roof Savings Calculator (RSC).

Below we discuss in further detail how objectives of the Project Advisory Committee (PAC) were met, the modern web technologies employed in the development of the calculator, usability considerations, and current functionality.

\section{Traceability}

The PAC defined a set of questions and answers that the calculator was to support both in the PAC meeting which convened March 6, 2008 as well as in the PAC quarterly report which was accepted January 21, 2009. In addition, the calculator was to support all relevant capabilities from other calculators while minimizing the number of questions a user must answer. The summary of comparative analysis between these calculators, documents, and the current version of the calculator are listed in Table 2. Input Comparison Chart.

The original calculator inputs included all fields listed in Table 2, but subsequent versions were refined by suggestions from teleconference meetings, review Figure 2 and Figure 3. These included the simplification of input by removing days of operation per week, internal load, and HVAC schedule since it was believed that we have fairly accurate data regarding prevalent parameters for these properties as a function of building type and that their presence would allow biased users to report unrealistic savings estimates. AtticSim does not support conditioned space under a roof so there is currently no modeling support for an attic-less cathedral roof. The RSC tool answers each of these questions by providing default answers selected from the best available statistics offered by the DOE's Energy Information Administration (EIA) [18], EPA's Energy Star [19] Program, and iterative expert review. For additional details, see Appendix A.

\section{Technologies}

Many current web technologies were employed in the development of the deployed calculator. The use of dynamic hypertext markup language (DHTML) includes technologies such as HTML and the HTML Document Object Model (HTML DOM) [20], cascading style sheets (CSS) [30], asynchronous JavaScript and XML (AJAX), and the Personal Home Page language (PHP) [22], as well as the jQuery [23] and jQuery User Interface (jQueryUI) Javascript library. The reasoning for employment of these 
technologies and their relevance to calculator capabilities, visibility, and maintenance are detailed below.

Table 2. Input Comparison Chart

\begin{tabular}{|c|c|c|c|c|c|}
\hline http://www.ornl.gov/btc/rsc & $\mathrm{RSC}^{[17]}$ & $\begin{array}{c}\text { PAC } \\
\text { Slides }\end{array}$ & $\begin{array}{l}\text { PAC } \\
\text { QRpt }\end{array}$ & $\mathrm{DOE}^{[15]}$ & $\operatorname{EPA}^{[16]}$ \\
\hline Building Type & 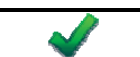 & 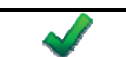 & 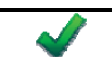 & & $\checkmark$ \\
\hline Location & $\sqrt{2}$ & 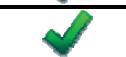 & & $\sqrt{2}$ & $\sqrt{2}$ \\
\hline Days of Operation per week & & $\vartheta$ & 8 & & 8 \\
\hline Building stock & 2 & 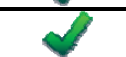 & & & 2 \\
\hline Cooling system efficiency (SEER) & 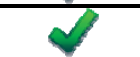 & $\Leftrightarrow$ &  & 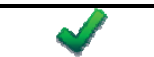 & 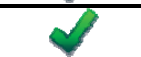 \\
\hline Type of heating & 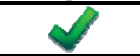 & $\vartheta$ & 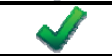 & $\vartheta$ & $\vartheta$ \\
\hline Heating system efficiency & $\vartheta$ & 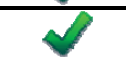 & 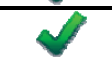 & 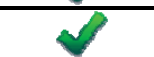 & 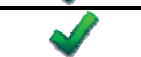 \\
\hline Duct location & $\sqrt{2}$ & 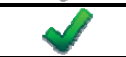 & $\sqrt{2}$ & & \\
\hline Level of roof/ceiling insulation & 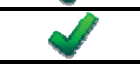 & $\checkmark$ & 2 & $\vartheta$ & $\vartheta$ \\
\hline Above-sheathing ventilation & 8 & 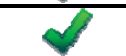 & & & \\
\hline Radiant barrier & $\%$ & 4 & & & \\
\hline Roof thermal mass & 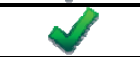 & 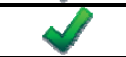 & & & \\
\hline Roof solar reflectance & 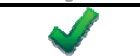 & $\checkmark$ & $\sqrt{2}$ & $\vartheta$ & 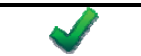 \\
\hline Roof solar reflectance (black compare) & $\%$ & & 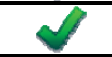 & & 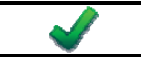 \\
\hline Roof thermal emittance & 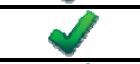 & $\vartheta$ & $\checkmark$ & $\vartheta$ & \\
\hline Roof thermal emittance (black compare) & 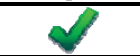 & & 4 & & \\
\hline Internal load & & 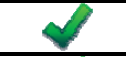 & & & \\
\hline Conditioned space under roof & & $\vartheta$ & & & \\
\hline Gas and electricity costs & 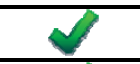 & $\vartheta$ & $\vartheta$ & $\vartheta$ & $\checkmark$ \\
\hline Inclination / Roof Area & $\vartheta$ & & & & 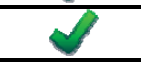 \\
\hline HVAC Schedule & & & 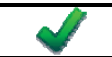 & & \\
\hline Conditioned space $\left(\mathrm{ft}^{2}\right)$ &  & & & & 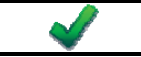 \\
\hline Number of floors & 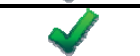 & & & & \\
\hline Window-to-wall ratio & 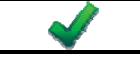 & & & & \\
\hline
\end{tabular}

DHTML is the art of making dynamic and interactive web pages. It typically combines HTML, JavaScript, the HTML DOM, and CSS. HTML and the HTML DOM are defined via specifications from the World Wide Web Consortium (W3C). HTML is the predominant markup language for web pages. It allows the use of "tags" (keywords surrounded by angle brackets) to denote structural semantics for a document. The HTML DOM is a cross-platform language-independent convention for interacting with HTML objects and thereby allows all computer types to interact via the internet. HTML DOM allows retrieval and operations on specific elements within the body of a page and is often used closely in combination with CSS.

CSS is a simple mechanism for adding style (e.g. fonts, colors, spacing) to Web documents. This logical separation of content and form through CSS offers several 
advantages: editing a single CSS file can make site-wide changes in seconds; logical handles (such as the class, name and id properties of div and span tags) allow precise simultaneous control of particular elements or group of elements; load times are improved due to browser caching and reduction in amount of formatting tags necessary; maintenance capabilities are improved due to cleaner code and separation of concerns; and better search engine placement due to proper HTML structure.

AJAX, coined by Jesse Garret in late 2005, is actually a group of interrelated web development techniques and technologies involving execution on the client-side to create interactive web applications. It allows program-level code to operate within web applications while retrieving data asynchronously from the server without interfering with the display or behavior of the existing page. AJAX was used extensively to provide an interactive web application that shows and hides relevant questions/answers based upon recent selections, updates default values between residential/commercial building types, and allows interactive switching between basic/advanced modes. The JavaScript Object Notation (JSON) lightweight data-interchange format [27] was used for transferring data, such as the formatted list of TMY2 city and states, between server and client. The drawbacks of AJAX include more complex code and thus longer development and maintenance efforts, often improper operation with the "back" button, reduced security, and the $~ 5 \%$ [24] of people who do not have JavaScript enabled for security reasons will be unable to use the dynamic content.

PHP is a general-purpose scripting language typically used to provide dynamic web content. PHP code is used in the calculator to dynamically generate a custom HTML response to the posted user selections and generate the back-end server response which displays energy and cost savings.

jQuery, initially released in 2006 and currently in active development, is a lightweight JavaScript library that facilitates interaction with HTML. It is the most popular JavaScript library in use as of the time of this writing and is used at $20 \%$ of the 10,000 largest websites [29]. jQuery allows efficient programming and reduced development times by providing a powerful application programming interface (API) which abstracts away many of the lower-level calls necessary in pure JavaScript. jQueryUI provides access to jQuery's visual controls and includes several core interaction plugins as well as many UI widgets. jQueryUI's Accordion widget was used to provide logical groupings of calculator form questions in a way that could be minimized when completed. Additional mouseover tooltips using jQueryUI’s BeautyTips is also planned for future calculator versions. The entire look-and-feel of the calculator was designed using jQueryUI's ThemeRoller [23] which provides a mechanism for immediately changing the calculator's look-and-feel based upon a custom, downloaded theme.

\section{Interface Design}

The calculator tool was designed to address several web usability issues [21][25][28]. Consistency is achieved through similar actions and wording required. User selection of radio buttons or entering text of custom values fits common user models. Consistent word phrases were chosen through based upon popularity according to Google search hits which also serves to increase visibility in the relevant domain. The input page is designed to yield closure by dividing the questions into logical groups related to 
building properties, heating/cooling, and roof comparison which constitute the beginning, middle, and end of the input process. Simple error handling and inline error message to highlight problematic manual entries is provided. Short-term memory load is reduced by simplified questions, answers, and page organization. Items are made visible only when relevant such as clicking the custom radio button makes the text box visible and also places the cursor in the box for the user to begin typing. Radio buttons, rather than dropdown boxes, were utilized heavily at the expense of screen space since they allow less cognitive overhead (the user is immediately aware of all available choices), label options for radio buttons are clickable to reduce selection time, and radio buttons require fewer and less accurate clicks than drop-down boxes.

The “7 plus/minus 2" principle was followed by organizing the page into essentially three levels: high-level groupings of building, utility cost; less than 7 questions in each of these sections, and relevant subproperties of these questions indented under the appropriate material. The Pareto principle was used to focus users on the subset of options which require input while assigning defaults all others. Fitt's Law was leveraged by providing immediate accessibility to all options as radio buttons and also making radio button labels clickable. The baby-duck syndrome was utilized by providing simple form input in the form of a short, multiple-choice test.

The Gestalt principle of proximity and similarity are evidenced in the logical grouping of questions; the law of symmetry was the basis for the black roof and white roof comparisons being symmetric across the page center. The calculator was not divided into multiple pages, but collapsible sections, since fold area is important but not crucial. Gloss is provided through mouse-over hints of where question helper links will take the user when clicked. Granularity has been addressed through collaborative reduction of input options. Readability has been enhanced by using web rank determination for question and answer phrasing. Walk-up-and-use design was implemented through page organization to allow a first-time user to quickly and easily run complex simulations. Defaults were set according to the best available statistics for every question except building location, allowing the calculator to be run simply after answering a single question. 


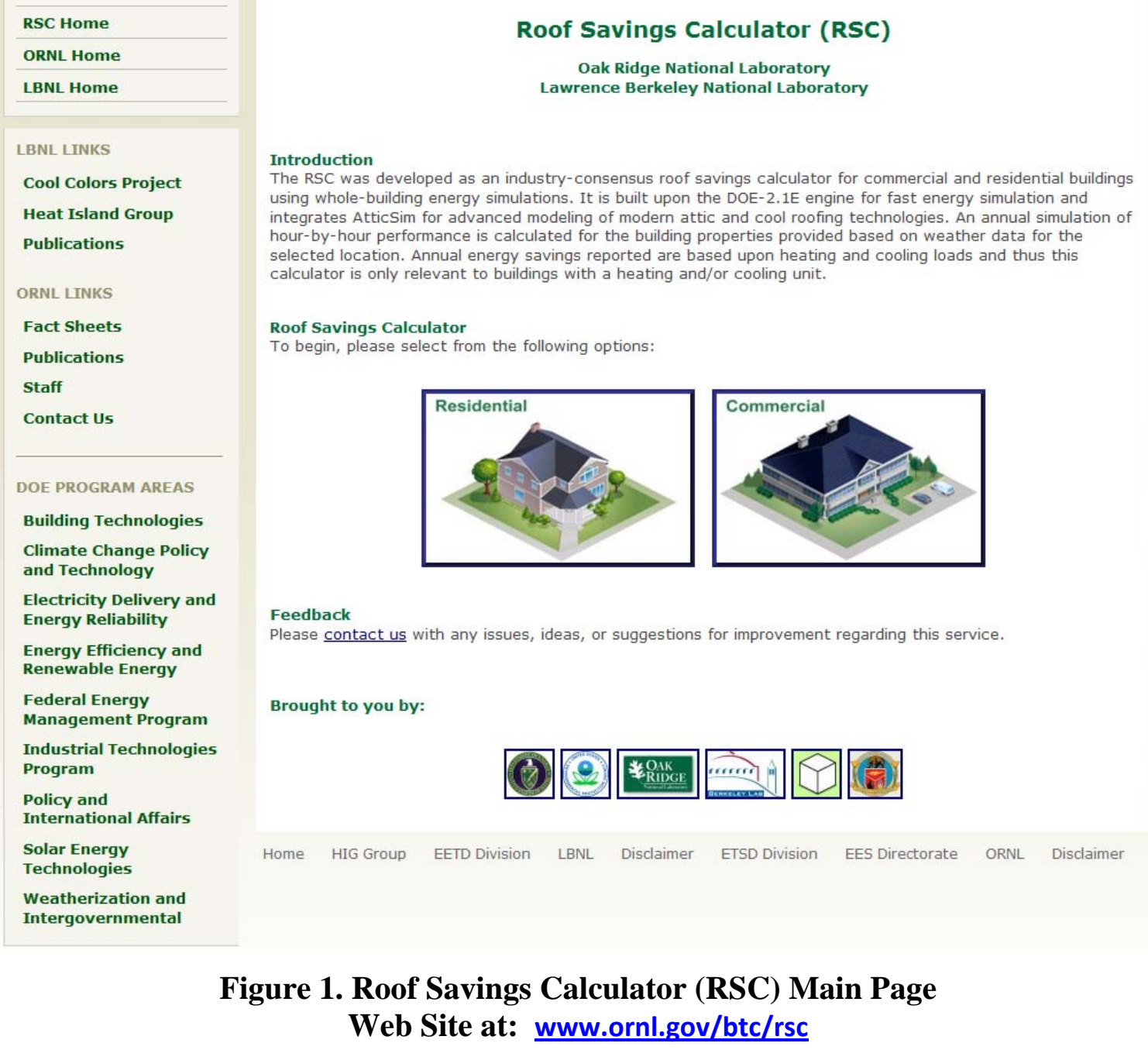




\section{Residential \\ Roof Savings Calculator (RSC)}

Go to: Advanced Mode

\section{Building}

1. Closest location (similar weather):

Select location

2. Building Type:

Residential -

3. Conditioned floor area $\left(\mathrm{ft}^{2}\right)$ : 0

2025

4. Number of floors:

1

5. Year of construction:

() post -1990

() 1980-1990

(C) pre- 1980

\section{Heating/Cooling}

6. Heating equipment:

Electric heat pump

- Natural gas furnace

Oil furnace

P1. Electricity price (cents per $\mathrm{kWh}$ ): (2) 11.68

P2. Natural gas price (dollars per $1000 \mathrm{ft}^{3}$ ): (2) 11.65

7. Heating system efficiency (AFUE): ?

High-efficiency (90\%)

( ) Mid-efficiency $(83 \%)$

Low-efficiency $(70 \%)$

Custom

8. Cooling system efficiency (SEER): ?

High-efficiency (15)

( ) Mid-efficiency (13)

Low-efficiency (10)

Custom

Figure 2. Roof Savings Calculator $-\mathbf{1}^{\text {st }}$ half 


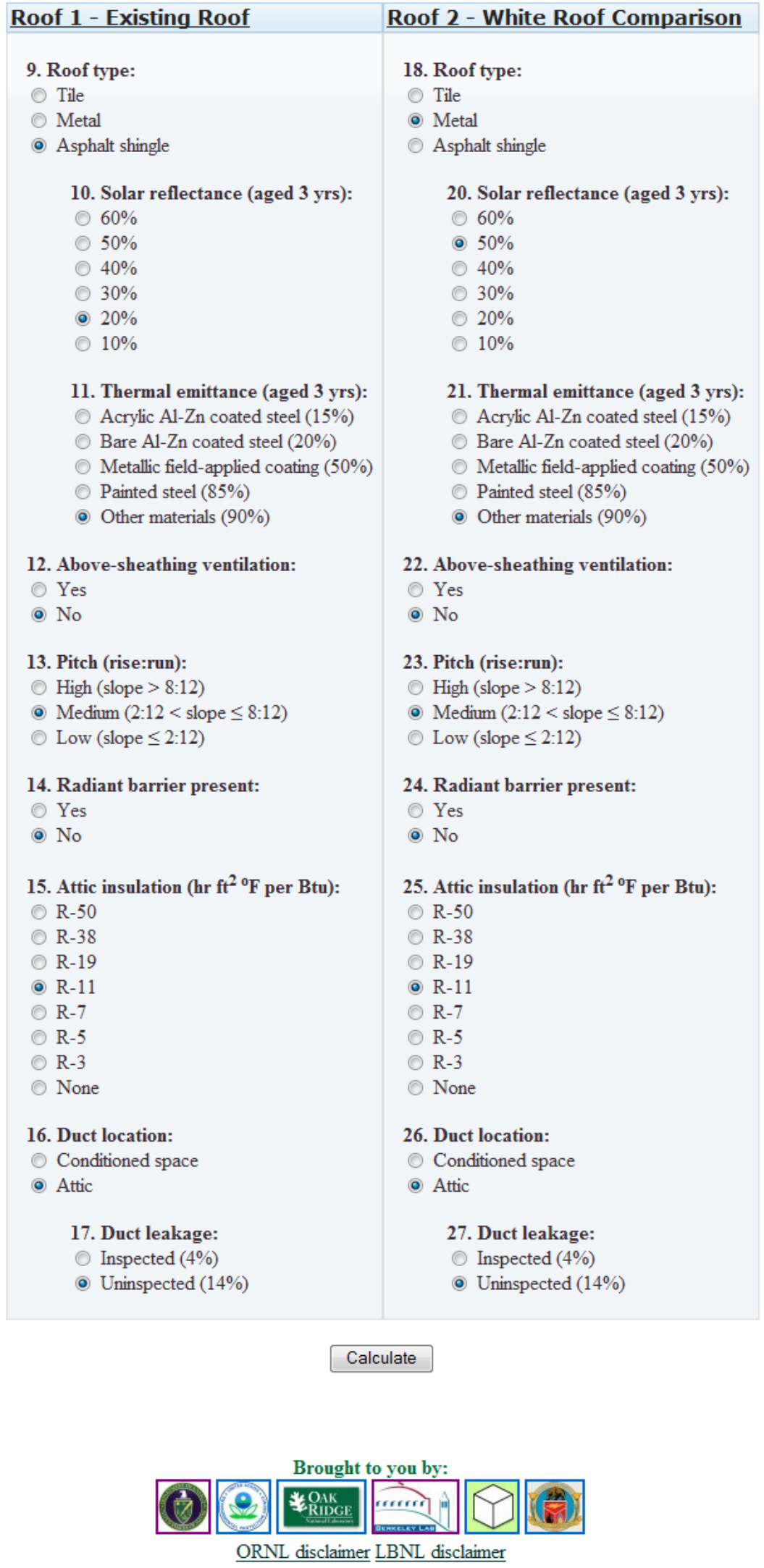

Figure 3. Roof Savings Calculator $-2^{\text {nd }}$ half 


\section{CALCULATOR BENCHMARK}

The 2003 F.W. Dodge [26] report shows tile roofs comprise $30 \%$ of the new and retrofit roof markets in CA. We therefore conducted field experiments in Southern California to benchmark both AtticSim as a stand alone tool and the new RSC tool. AtticSim has a history of validations against several different profiles of tile, stone-coated metal, asphalt shingle and standing seam metal roofs, all of which were field tested at ORNL. However, AtticSim was also benchmarked against two of the Ft Irwin homes to assist White Box Technology with its benchmark of the RSC tool.

The four demonstration homes were setup for making two bases of comparison: 1) concrete tile applied directly to the deck, one coated with a cool color coating the other not coated, and 2) concrete tile elevated 11/2-in $(0.038-\mathrm{m})$ above the deck, one roof coated with a cool color coating the other not coated. AtticSim was benchmarked against House N5 for summer data (Aug. 2008) and House N8 for winter data (Feb 2008). During these periods tenants were paid a $\$ 200$ per month incentive to keep their thermostats at $72^{\circ} \mathrm{F}$ $\left(22.2^{\circ} \mathrm{C}\right)$. House N5 has the tile attached directly to the deck (labeled D-t-D) with the tile painted with COOLTILE IR COATINGS ${ }^{\mathrm{TM}}$ by American RoofTile Coatings. House N8 had conventionally painted the tile placed on double battens (labeled DB).

\section{AtticSim Benchmark of House N5}

The solar irradiance from pyranometers fixed to the sloped roof surfaces, and the weather data were used by AtticSim to compute the surface temperature of the tile, the air temperature in the inclined air space made by the tile, the heat flux crossing the roof decks, the attic air temperature and the heat flow crossing the attic floor. Measured temperature at the thermostat was also used by AtticSim to estimate convection effects from the ceiling into the conditioned space.

Estimates had to be made of the airflow induced by a solar fan installed on the south facing roof. All homes had these fans which energized whenever the photovoltaic panel generated enough current to drive the fan. However, results show that AtticSim simulated the attic air temperature within about $\pm 2^{\circ} \mathrm{F}\left(0.6^{\circ} \mathrm{C}\right)$, Fig. $4 \mathrm{a}$.

The heat flux crossing the south facing roof deck was accurately computed by AtticSim as compared to the flux measured by heat flux transducers (installed on underside of roof deck). Figure $4 \mathrm{~b}$ shows that AtticSim was also able to follow the diurnal trends in heat flows crossing the attic floor having $\mathrm{R}_{\mathrm{US}} 38\left(\mathrm{R}_{\mathrm{SI}} 6.7\right)$ fiberglass batt insulation. The peak day values between AtticSim and measured ceiling heat flows are within about 5\% of measure; however, measured data lags AtticSim predictions and is believed due to the truss system in the attic. Additional simulation work will be conducted to check whether the truss system affects the predictions. 


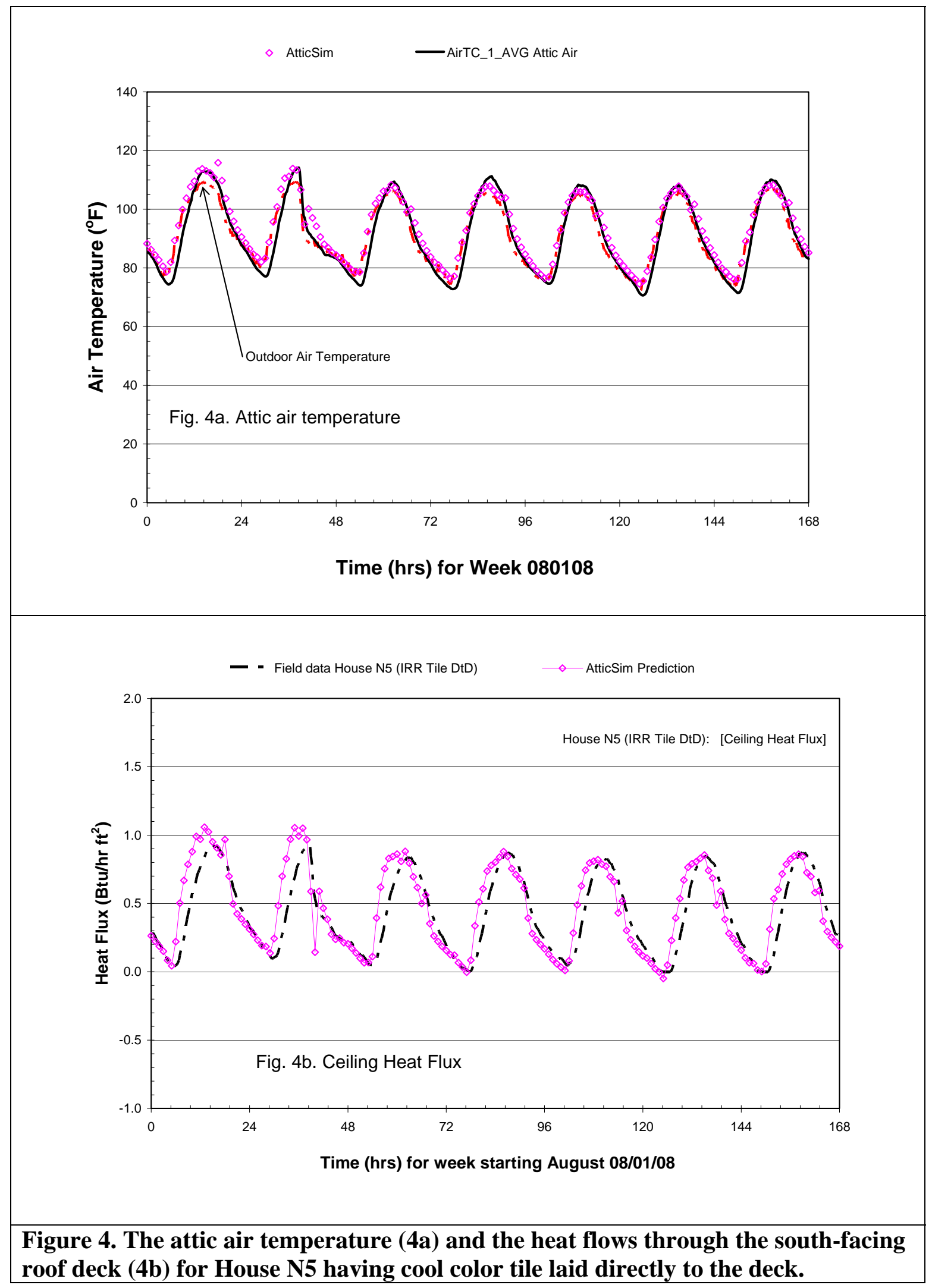




\section{AtticSim Benchmark of House N8}

The air temperature in the inclined air space formed by the double batten arrangement of the concrete tile is shown in Figure 5 for data collected during February 2008. Again the solar irradiance was input AtticSim from pyranometers fixed to the sloped roof surfaces, and the weather data were used in AtticSim to compute the thermal performance of the roof and attic. The code well replicated the measured air temperature in the ventilated space under the tile. Miller et al. [12] provide details of the energy balance for interior duct flow that is used to compute the air temperature in the air space.

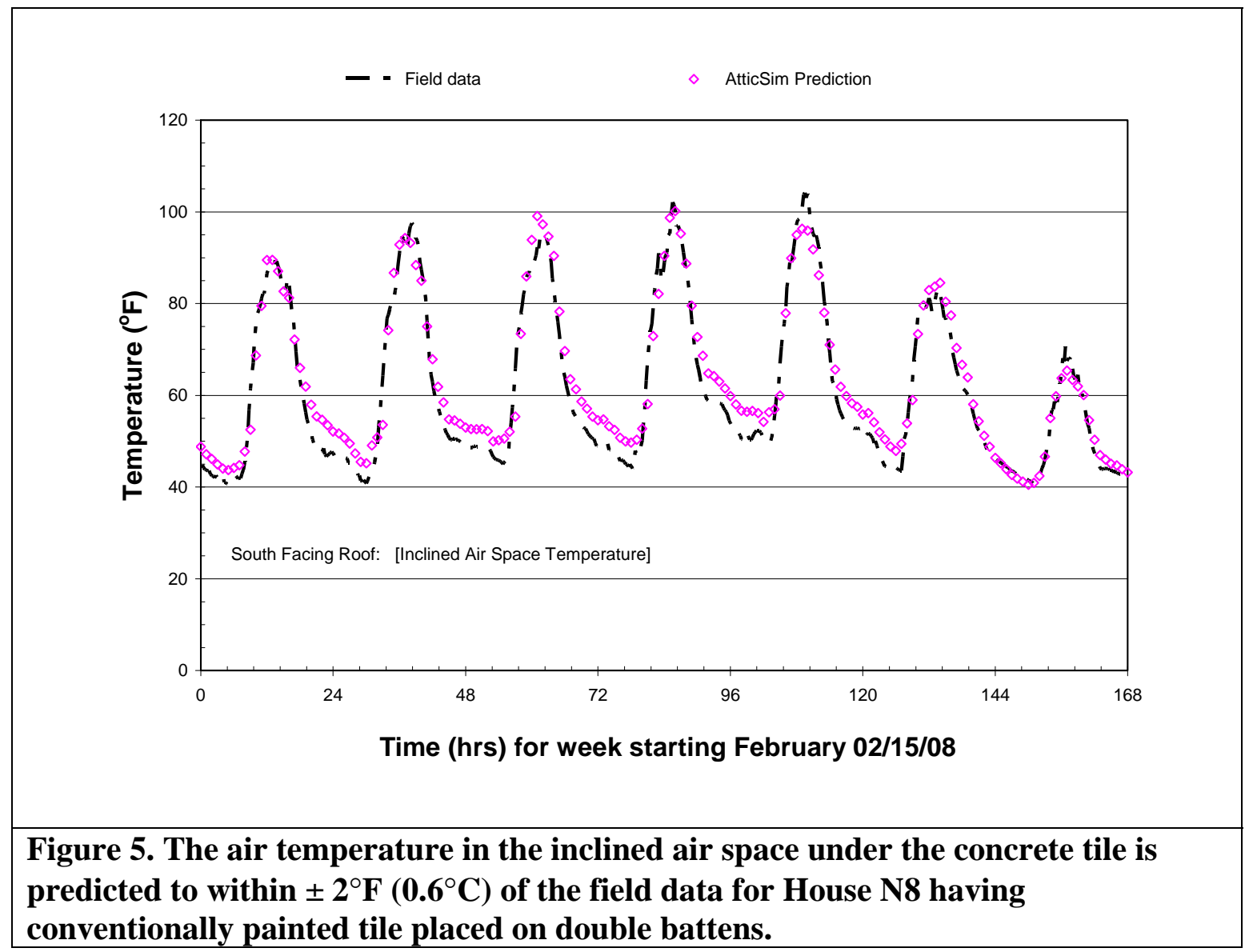

For this February week of data, the outdoor air temperature peaks at about $68^{\circ} \mathrm{F}$ $\left(20^{\circ} \mathrm{C}\right)$ during the day and drops to about 50 to $40{ }^{\circ} \mathrm{F}\left(10\right.$ to $\left.4.4^{\circ} \mathrm{C}\right)$ at night. Therefore the ceiling heat loads are relatively small and did not exceed $\pm 0.5 \mathrm{Btu} /\left(\mathrm{hr} \mathrm{ft}^{2}\right)\left[0.16 \mathrm{~W} / \mathrm{m}^{2}\right]$. Yet results show that AtticSim simulated the daily trends in ceiling heat flux relatively well, Fig. 6. During the daytime the predicted and measured flux are not accurate and differ by about $0.25 \mathrm{Btu} /\left(\mathrm{hr} \mathrm{ft}^{2}\right)\left[0.08 \mathrm{~W} / \mathrm{m}^{2}\right]$. This occurs because the temperature difference across the $\mathrm{R}_{\mathrm{US}} 38\left(\mathrm{R}_{\mathrm{SI}} 6.7\right)$ batt insulation is at best only $3.6^{\circ} \mathrm{F}\left(2^{\circ} \mathrm{C}\right)$, while at night the temperature drop across the ceiling insulation is about $14.4^{\circ} \mathrm{F}\left(8^{\circ} \mathrm{C}\right)$. Therefore the error is primarily due to the uncertainty of the temperature measurements. 


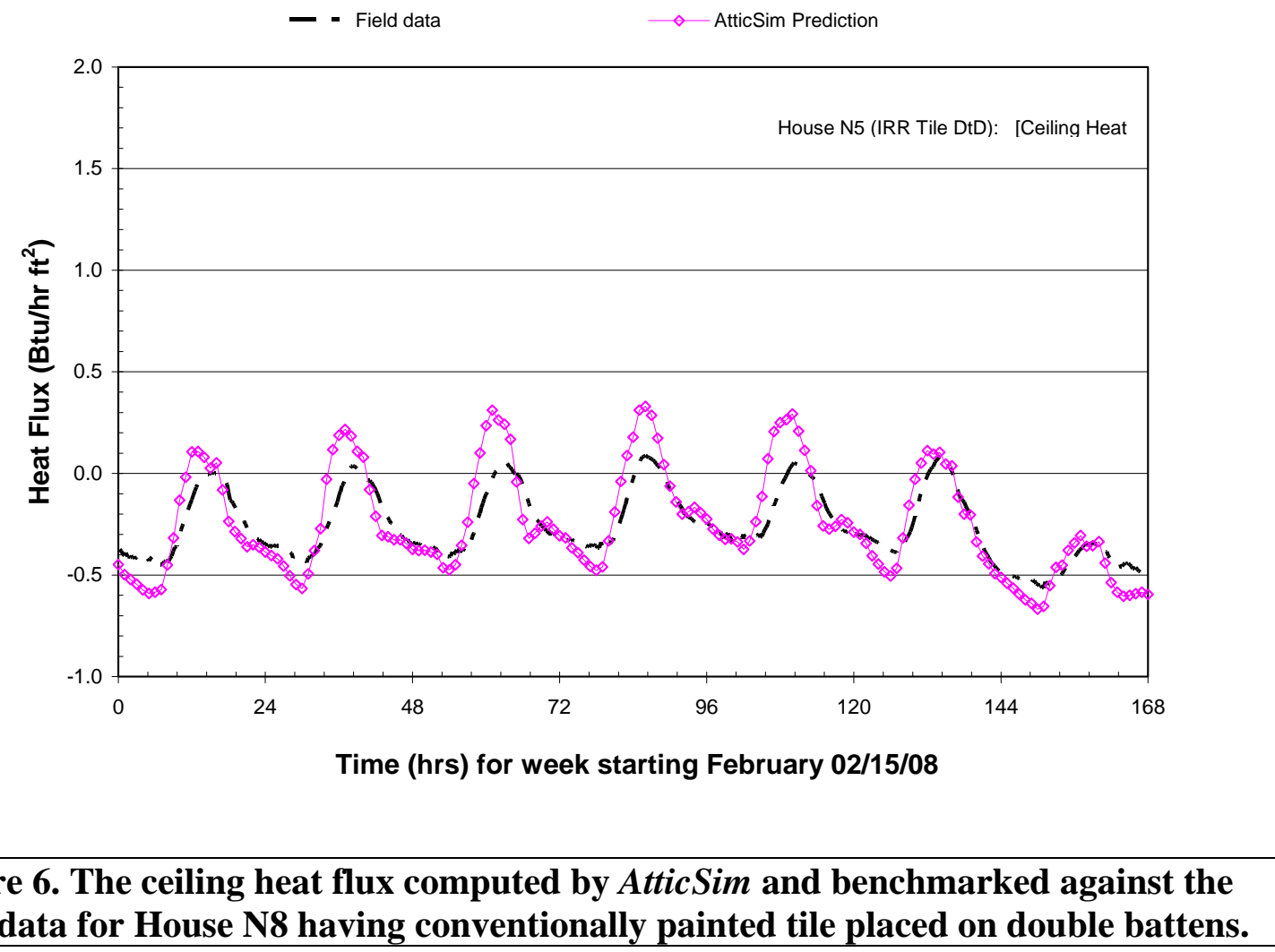

\section{DOE-2.1E/AtticSim Benchmark of Houses N5 and N8}

We repeated the simulations described above for House N5 using the August 08 week of field data and for House N8 using the February 08 data with the combined DOE2.1E/AtticSim code. Testing determined whether AtticSim worked properly within DOE2.1E for the thermal exchange through the attic floor (i.e., house ceiling) and for the data exchange about HVAC operations and duct losses. Both of these issues are complex, since they are nonlinear as well as interrelated. The heat flows through the attic floor, which are critical for determining the energy savings from attic conservation measures, are further complicated by the fact that DOE-2 uses several sequential steps to derive net zone heat flows, so that in coupling DOE-2 with AtticSim it has been necessary to disable some of these steps to prevent double counting. To calculate the duct losses, AtticSim needs to know the on-time for the HVAC system, but that is not known until further into the simulation process. Ultimately, it was found necessary to model the attic twice, once with DOE-2 and then again with AtticSim.

Figure 7 is similar to Figure 4a, but this time showing the attic air temperatures modeled with the combined DOE-2/AtticSim program rather than with the standalone AtticSim program. 


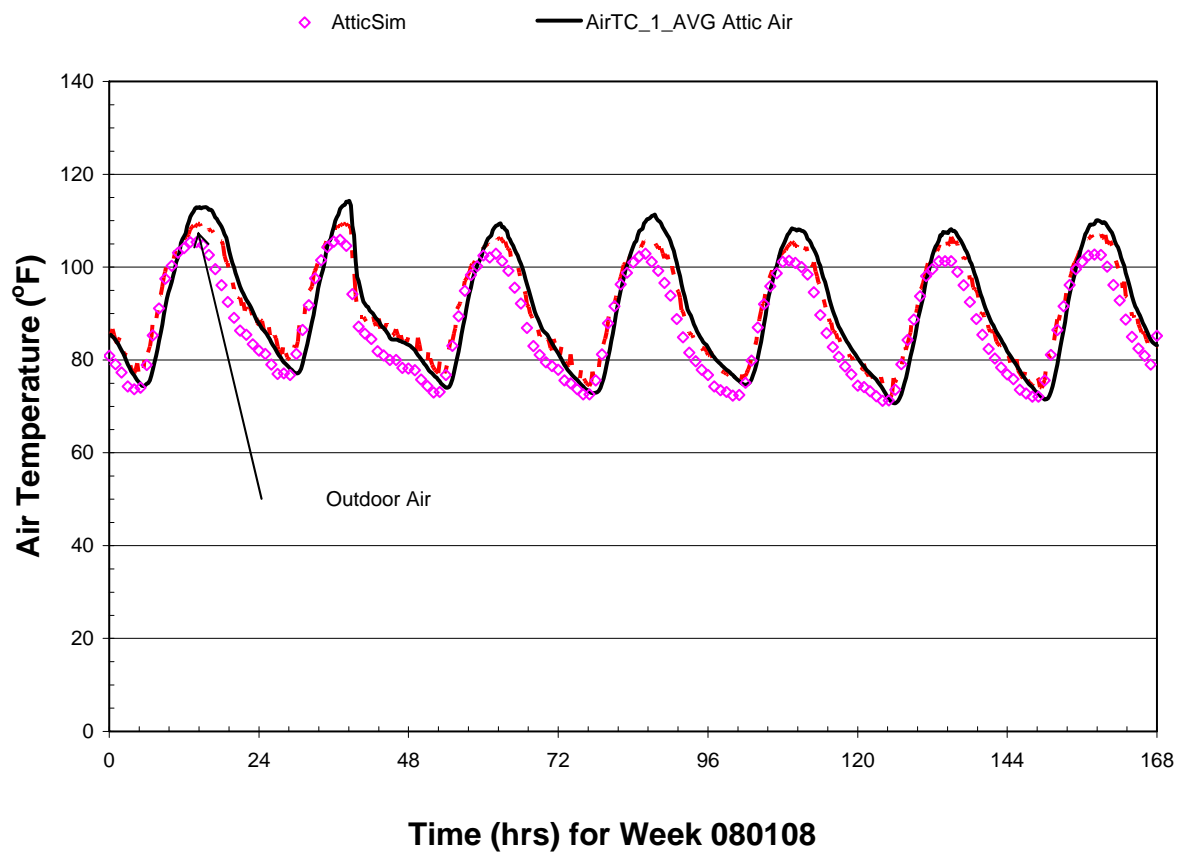

\section{Figure 7. Comparison of DOE-2.1E/AtticSim to measured attic temperatures for House N5 collected August 08.}

In comparison to Figure 4a, the attic temperatures shown by the combined DOE2.1E/AtticSim code are lower. This may be due to either differences in how the attic is being modeled as compared to the standalone AtticSim simulation, or to double-counting of ceiling heat flows in the draft version of the DOE-2.1E/AtticSim program.

Figure 8 shows the attic air temperatures modeled with the combined DOE2/AtticSim program for House N8 as compared to measured data field data for February 08. Here again the attic temperatures shown by the combined DOE-2.1E/AtticSim program matches the measured minima, but are consistently several degrees lower than the daily maxima. This again may be due to double-counting of ceiling heat flows in the draft version of the DOE-2.1E/AtticSim program. 


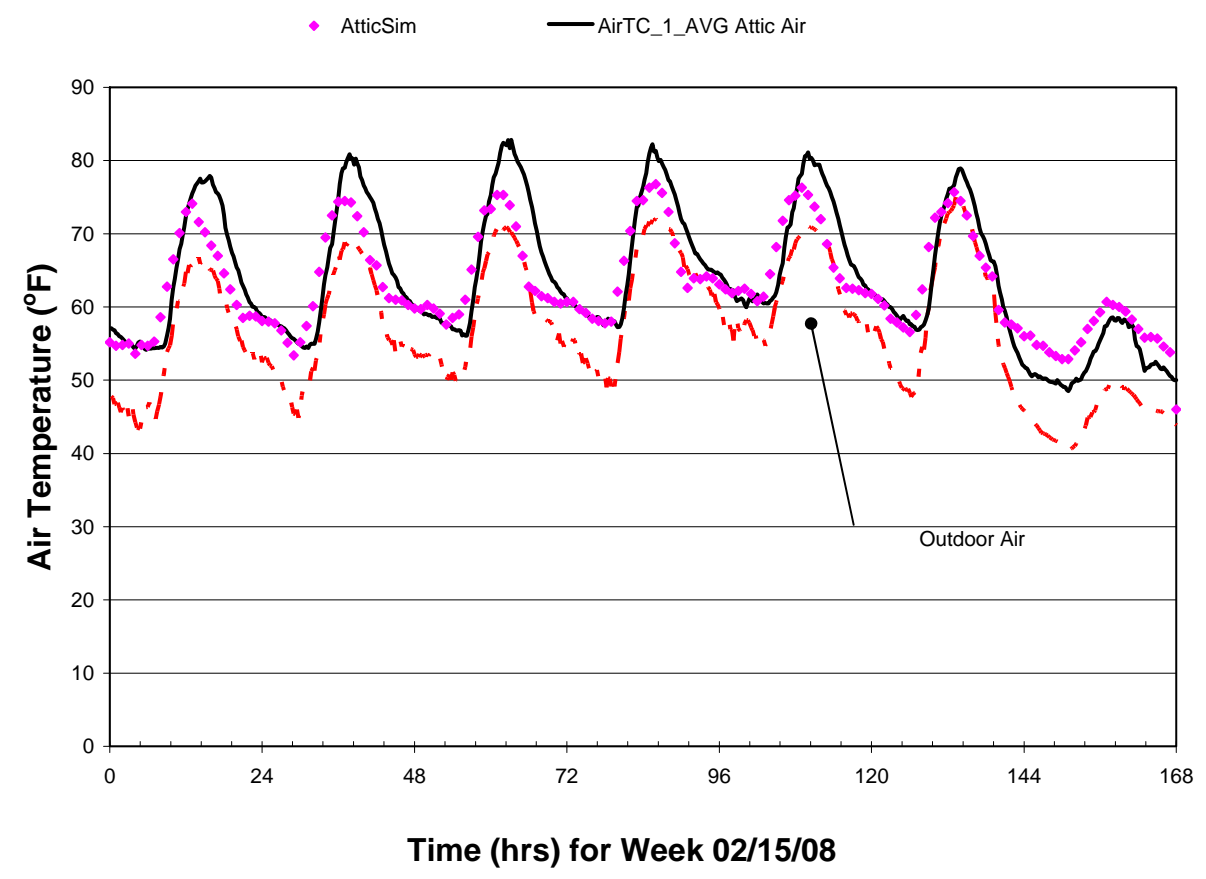

Figure 8. Comparison of DOE-2.1E/AtticSim to measured attic temperatures for House N8 collected February 2008.

\section{CONCLUSIONS}

In conclusion, the RSC [17] provides an approachable portal for both industry experts and residential homeowners to leverage the best available whole-building energy simulation packages and determine energy and cost savings for modern roof technologies and related retrofits. The managers of the DOE and EPA calculators have agreed to take down their calculators and refer all users to a single universally acceptable energy estimating tool.

The tool uses the DOE-2.1E whole-building energy simulation program and calls AtticSim from the SYSTEMS module where AtticSim computes the temperatures and heat flows of all surfaces in the attic and passes back to DOE-2.1E the attic air temperature, the duct gains and losses and the ceiling heat flow. For all simulations the attic floor is assumed sealed with no air leakage crossing from the conditioned space into the attic. The two codes merged together run an annual simulation in about $30 \mathrm{sec}$.

Combined, the two codes offer in the RSC a powerful feature that was benchmarked against field data for CA demonstration homes collected at Ft Irwin. Hence, the tool was shown to yield credible results and the new tool is a real-time calculator (loaded on the internet).

\section{ACKNOWLEDGEMENTS}

Funding for this project was provided by the California Energy Commission's Public Interest Energy Research program through the U. S. Department of Energy under contract DE-AC03-76SF00098. Oak Ridge National Laboratory is managed by UTBattelle, LLC, for the U.S. Dept. of Energy under contract DE-AC05-00OR22725. The 
submitted manuscript has been authored by a contractor of the U.S. Government under contract DE-AC05-00OR22725. Accordingly, the U.S. Government retains a nonexclusive, royalty-free license to publish or reproduce the published form of this contribution, or allow others to do so, for U.S. Government purposes.

\section{DISCLAIMERS}

Mention of the trade names, instrument model and model number, and any commercial products in the manuscript does not represent the endorsement of the authors nor their employer, the Oak Ridge National Laboratory or the US Department of Energy.

\section{NOMENCLATURE}

\begin{tabular}{|l|l|}
\hline AJAX & Asynchronous JavaScript and XML \\
\hline API & application programming interface \\
\hline CSS & Cascading Style Sheets \\
\hline DHTML & Dynamic HyperText Markup Language \\
\hline DOE & Department of Energy \\
\hline DOM & Document Object Model \\
\hline EPA & Environmental Protection Agency \\
\hline HVAC & Heating Ventilation and Air Conditioning \\
\hline JSON & JavaScript Object Notation \\
\hline PHP & Personal Home Page \\
\hline PVC & polyvinylchloride thermoplastic membranes \\
\hline PIER & Public Interest Energy Research \\
\hline RSC & Roof Savings Calculator \\
\hline SR & solar reflectance \\
\hline TE & thermal emittance \\
\hline$R_{U S}$ & Thermal resistance $\left(\mathrm{hr}_{\mathrm{ft}}{ }^{2} \mathrm{~F}\right)$ per Btu \\
\hline RSI & Thermal resistance $\left(\mathrm{m}^{2} \mathrm{~K}\right)$ per Watt \\
\hline
\end{tabular}

\section{RECOMMENDATIONS}

Sensitivity runs are needed to judge the stability of the new tool's solution procedure. Therefore, it is recommended to continue using the demonstration data for $\mathrm{Ft}$ Irwin and also for Northern CA in Redding to complete a unique benchmark of the RSC tool that few whole building codes have documentation to distinguish their code's credibility. The RSC tool also requires beta testing by the roofing community.

\section{REFERENCES}

[1] Los Alamos Scientific Laboratory (1980). DOE-2 Reference Manual, Parts 1 and 2, Version 2.1. LA-7689-M Ver. 2.1, LBL-8706 Rev. 1, Lawrence Berkeley Laboratory, Berkeley CA and Los Alamos Scientific Laboratory, Los Alamos NM.

[2] Lawrence Berkeley Laboratory (1982). DOE-2 Engineers Manual, Version 2.1A. Lawrence Berkeley Laboratory, Berkeley CA. 
[3] Winkelmann, F., Birdsall, B., Buhl, F., Ellington, K., Erdem, E., Hirsch, J., and Gates, S. (1993). DOE-2 Supplement, Version 2.1E. LBL-34947, Lawrence Berkeley National Laboratory, Berkeley CA.

[4] Huang, Y.J., Mitchell, R., Arasteh, A., and Selkowitz, S. 1999. "Residential fenestration performance analysis using RESFEN 3.1”, Thermal Performance of the Exterior Envelopes of Building VII conference, Clearwater Beach FL, also LBNL42871.

[5] Huang, Y.J., Akbari, H., Rainer, L., and Ritschard, R.L. 1990. "481 prototypical commercial buildings for twenty urban market areas (Technical documentation of building loads data base developed for the GRI Cogeneration Market Assessment Model)", LBL Report 29798.

[6] Torcellini, P., Deru, M., Griffith, G., Benne, K., Halverson, M., Winiarski, D., and Crawley, D. 2008. "DOE Commercial Building Benchmark Models”. 2008 ACEEE Summer Study on Energy Efficiency in Buildings, Pacific Grove CA.

[7] [ASTM] American Society for Testing and Materials. 2004. Standard Practice for Estimation of Heat Gain or Loss through Ceilings under Attics Containing Radiant Barriers by Use of a Computer Program. Standard C 1340-04. West Conshohocken, Penn.: American Society for Testing and Materials.

[8] Petrie, T. W., T. K. Stovall, and A. O. Desjarlais. 2004. “Comparison of Cathedralized Attics to Conventional Attics: Where and When Do Cathedralized Attics Save Energy and Operating Costs?” Thermal Performance of the Exterior Envelopes of Buildings IX, Atlanta: American Society of Heating, Refrigerating and Air-Conditioning Engineers.

[9] Parker, D., P. Fairey, and L. Gu. 1993. "Simulation of the Effects of Duct Leakage and Heat Transfer on Residential Space Cooling Energy Use.” Energy and Buildings, 20(2): 97-113.

[10] Petrie, T. W., K. E. Wilkes, P. W. Childs, and J. E. Christian. 1998. "Effect of Radiant Barriers and Attic Ventilation on Residential Attics and Attic Duct Systems: New Tools for Measuring and Modeling,” ASHRAE Trans., vol. 104, 1175-1192.

[11] Ober, D.G. and Wilkes, K.E. 1997. “An Energy Calculation Method for Attics, Including Radiant Barriers,” ASHRAE Research project RP717 for TC4.7, Feb. 1997.

[12] Miller, W. A. 2006. The Effects of Infrared-Blocking Pigments and Deck Venting on Stone-Coated Metal Residential Roofs. ORNL/TM-2006/9. Oak Ridge, Tenn.: Oak Ridge National Laboratory.

[13] Miller, W. A., M. Keyhani, T. Stovall and A. Youngquist. 2007. "Natural Convection Heat Transfer in Roofs with Above-Sheathing Ventilation,” in Thermal Performance of the Exterior Envelopes of Buildings X. Atlanta: American Society of Heating, Refrigerating and Air-Conditioning Engineers.

[14] Stephenson, D. G. and Mitalas, G.P. (1981) “Calculation of Heat Conduction Transfer Functions for Multi-Layer Slabs,” ASHRAE Transactions 77, Part II, 117. 
[15] Department of Energy, “DOE Cool Roof Calculator,” Oak Ridge National Laboratory, http://www.ornl.gov/sci/roofs+walls/facts/CoolCalcEnergy.htm.

[16] Environmental Protection Agency, "Roofing Comparison Calculator," Environmental Protection Agency, http://www.roofcalc.com/RoofCalcBuildingInput.aspx.

[17] Miller, W.A, J.R. New, J. Huang, E. Erdem, et al., "Roof Savings Calculator," www.ornl.gov/btc/rsc

[18] U.S. Energy Information Administration, "Independent Statistics and Analysis," http://www.eia.doe.gov.

[19] U.S. Environmental Protection Agency, “Energy Star,” http://www.energystar.gov/

[20] World Wide Web Consortium (W3C), "HTML 4.01 Specification,” http://www.w3.org/TR/html4.

[21] Friedman, Vitaly, "30 Usability Issues to be Aware of,” http://www.smashingmagazine.com/2007/10/09/30-usability-issues-to-be-aware-of

[22] Lerdor, Rasmus, "PHP: Hypertext Processor,” http://php.net/index.php

[23] Resig, John, “jQuery project,” http://jqueryui.com/themeroller.

[24] W3Schools, "Web Statistics and Trends," http://www.w3schools.com/browsers/browsers_stats.asp

[25] Shneiderman, Ben and Plaisant, Catherine (2004). "Designing the User Interface: Strategies for Effective Human-Computer Interaction,” isbn:0321197860.

[26] F. W. Dodge. 2002. “Construction Outlook Forecast.” www.fwdodge.com. F.W. Dodge Market Analysis Group, Lexington, Mass.

[27] JavaScript Object Notation Organization, “Introducing JSON,” http://www.json.org/

[28] Nielsen, Jakob, “Jakob Nielsen on Usability and Web Design,” http://www.useit.com/alertbox.

[29] Nordenstam, Olof, "Backend Battles - What the biggest websites have in common,” http://www.backendbattles.com/backend/jQuery.

[30] World Wide Web Consortium (W3C), "Cascading Style Sheets," http://www.w3.org/Style/CSS. 


\section{APPENDIX A}

Joint teleconferences were hosted by Joshua New with all stakeholders regarding design decisions, web layout, appropriate questions and default values, order of energy-efficient options, and other implementation-level issues. The meeting minutes regarding the final form and justifications for the calculator design are provided below.

\section{Meeting \#1 Minutes}

\section{Meeting Minutes}

Date: $\quad$ November 19, 2009

From: Joshua R. New (newjr@ornl.gov), 3147, Room 210, MS 6070, 865-241-

8783

Subject: $\quad$ [RSC] Roof Savings Calculator - Meeting Minutes \#1 (Addressed)

I) Meeting \#2 Schedule (12/14/09-12/18/09):

Please take a minute to complete the Doodle poll by *Sunday, December $13 *$ by selecting the dates and times that are convenient for you:

http://www.doodle.com/gs7fh5a9xxk3zn3z

Note: The final meeting time will be sent the morning of Monday, December 14

\section{II) Roof Savings Calculator 0.2 link:}

The latest version for discussion purposes and feedback from colleagues can be found at: http://www.cs.utk.edu/ new/rsc2/rsc.htm?mode=adv

Note: Commercial questions are denoted C1, Residential questions are denoted R1, Simple-mode questions are denoted S1, and Advanced-mode questions are denoted A1

All feedback should be directed to:

Joshua New, ORNL - newjr@ornl.gov

III) Meeting Minutes (11/12/09)

\section{1) Invitees}

DOE: $\quad$ Marc LaFrance (Marc.Lafrance@ee.doe.gov)

ORNL: Andre Desjarlais (desjarlaisa@ornl.gov)

Bill Miller (millerwa1@ornl.gov)

Joshua New (newjr@ornl.gov)

WhiteBox: Joe Huang (yjhuang@whiteboxtechnologies.com)

Ender Erdem (ender.erdem1@gmail.com) - recently retired LBNL

LBNL: Ronnen Levinson (RML27@cornell.edu)

Haley Gilbert (hegilbert@lbl.gov) 
Concordia:Hashem Akbari (HAkbari@ENCS.Concordia.CA)

CEC: $\quad$ Chris Scruton (Cscruton@energy.state.ca.us) - absent Norman Bourassa(Njbouras@energy.state.ca.us)

EPA: Steven Ryan (Ryan.Steven@epamail.epa.gov) - absent Neelam Patel (Patel.Neelam-R@epamail.epa.gov)

\section{2) Action Items}

a) Color codes (Word document attached for anyone using mail clients without HTML/color support):

Change (blue)

Addition (green)

Advanced mode (brown)

Phase II possibility (red)

b) Calculator link of version being referenced by Meeting Notes: http://www.cs.utk.edu/ new/rsc1/bec.htm?calc=Com

c) Meeting Notes:

Meeting Info:

- Marc LaFrance recommended

○ Monthly Meetings (Doodle meeting planner link at top)

- Marc LaFrance recommended an alpha version release and feedback (Norman Bourassa concurred based on previous work)

- An updated version, with link, will be made available before the next meeting and can be shared with others

○ A SurveyMonkey link will be provided for gathering feedback

General:

- Change name to: Roof Savings Calculator

- Support for more building types (Office-20\%, Warehouse-14\%, and School-13\% originally chosen based on percentage of national footprint). Joe Huang stated offices, warehouses, schools, and stores are same building characteristics as used by PNNL in support of ASHRAE-90.1

○ Participants opted to substitute Box Stores for schools

○ Options for more building types is a Phase II initiative

\section{Closest location}

- Ronnen Levinson and Hashem Akbari suggested zip code location instead of TMY2 drop-down

- Support for zip code or map location is a Phase II initiative 
2. Conditioned area $\left(\mathrm{ft}^{2}\right)$ :

- Ronnen Levinson suggested rephrasing to

○ 2. "Conditioned floor area..."

4. Window-to-wall ratio:

- Joe Huang recommended eliminating 4. Number of Windows

- Andre Desjarlais recommends adding default

- Will be relegated to advanced mode

5. Building Stock:

○ Pre-1980

- 1980-1990

○ Post-1990

6. Internal load and 7. Days of Operation per week:

- Joe Huang proposed adding "6. Internal load" and "7. Days of Operation” to advanced mode

○ Will be relegated to advanced mode

8. Type of heating:

- Haley Gilbert suggested no cooling as an option

○ Support for internal temperatures (for $3^{\text {rd }}$ world countries) is a Phase II initiative

○ Directions will be given to inform user this tool is only for residences with a cooling unit

8. Type of heating:

- Bill Miller suggested

○ Rewording as "Type of heat/cool unit"

9. Heating system efficiency (SEER):

- Ronnen Levinson and Hashem Akbari suggested

- HSPF (Heating Seasonal Performance Factor ) for Heating performance

- SEER (Seasonal Energy Efficiency ratio) for Cooling performance

9. Heating system efficiency (SEER):

- Bill Miller suggested furnace efficiency for gas furnace

○ Will replace question 9 accordingly

9. Heating system efficiency (HSPF) and 10. Cooling system efficiency (SEER):

- Marc LaFrance suggested

○ "advanced", "standard", and "old" mode

○ Numbered efficiencies relegated to advanced mode

11. Duct location: 
- Hashem Akbari recommended "No ducts” and Marc LaFrance "ductwork above roof plane". AtticSim does not model ductwork above the roof, Hashem Akbari has a model that could serve as a basis for this extension.

○ Ductwork above the roof plane is a Phase II initiative

13. Gas price (cents per therm):

- Ronnen Levinson pointed out units are different between cents-per-therm in the calculator and USD-per-1k-cubic-feet in link

○ Consistent units between question and web price reference will be used

- Norman Bourassa and Haley Gilbert recommended

○ Question mark/links opening in another window

15. Level of insulation:

- Ronnen Levinson recommended R-50 (with hyphen) to clarify units

○ Rus-50 will be utilized having units [hr ft2 oF per Btu]

17. Inclination (rise/run):

- Ronnen Levinson rise:run (rather than rise/run) and Hashem Akbari concurred

○ Rise:run will be used

18. Thermal mass:

- Ronnen Levinson and Bill Miller discussed various commercial roof types:

Thermoplastic membranes (TPO,PVC), Bitmens (asphault), Built-up roof (BUR), Pavers (concrete), and Ballasted Roofs

- All will be added in cool roof section as roof type

○ Options for ballast roof is a Phase II initiative (porous media not modeled by AtticSim)

18. Thermal mass:

- Norman Bourassa recommended rephrasing to

○ Roof thermal mass

20. Solar reflectance and 21 . Thermal emittance:

- Hashem Akbari recommended custom solar reflectance and emittance

○ "Other" button will be added

Others:

- Norman Bourassa recommended

○ (Commercial version roof grouping): "Plenum/Roof - Your building”

- Norman Bourassa recommended ASV be changed to offset mounting

○ Will use "offset mounted roof" (with help introducing the ASV work from ORNL) 
- Marc LaFrance recommended keeping offset mounting (to promote the technology) rather than removing it

○ Accepted

Calculate button

- Joe Huang working to refine output, Hashem Akbari asked if it would give peak demand

○ Outputs will include: heating and cooling load for summer and winter, dollar annual savings for heating and cooling, and peak demand

Pricing models

- Support only for utility rates will be utilized

○ Other pricing models (such as on-peak and off-peak pricing) is a Phase II initiative

\section{Meeting \#2 Minutes}

Date: $\quad$ December 19, 2009

From: J. R. New (newjr@ornl.gov), 3147, Room 210, MS 6070, 865-241-8783

Subject: [RSC] Meeting \#2 - Addressed

I) Meeting \#3 Schedule (1/20/10):

Teleconference date: Wednesday, Jan. 20th

Teleconference start time: 3:00-4:00pm EST (12:00 noon - 1:00pm PST)

Dial-in (toll-free) number: (866) 564-1870

Confirmation number: 4558717

Based on doodle availability: http://www.doodle.com/8uteaa77su3r7x8n

\section{II) Roof Savings Calculator (v0.3) link:}

The latest version for discussion purposes and feedback from colleagues can be found at: http://www.ornl.gov/btc/rsc

All feedback should be directed to:

Joshua New, ORNL - newjr@ornl.gov

III) Meeting Minutes (12/15/09)

\section{1) Invitees}

DOE: Marc LaFrance (Marc.Lafrance@ee.doe.gov) - present

ORNL: Andre Desjarlais (desjarlaisa@ornl.gov) 
Bill Miller (millerwa1@ornl.gov)

Joshua New (newjr@ornl.gov) - present

WhiteBox: Joe Huang (yjhuang@whiteboxtechnologies.com)

Ender Erdem (ender.erdem1@gmail.com)

LBNL: Ronnen Levinson (RML27@cornell.edu) - present

Haley Gilbert (hegilbert@lbl.gov)

Concordia:Hashem Akbari (HAkbari@ENCS.Concordia.CA)

CEC: Chris Scruton (Cscruton@energy.state.ca.us) - present

Norman Bourassa(Njbouras@energy.state.ca.us)

EPA: $\quad$ Steven Ryan (Ryan.Steven@epamail.epa.gov)

Neelam Patel (Patel.Neelam-R@epamail.epa.gov)

\section{2) Action Items}

a) Color codes (Word document attached for anyone using mail clients without HTML/color support):

Change Implemented or Suggestion Accepted (blue)

Suggestions for discussion (red)

b) Calculator link of version being referenced by Meeting Notes:

http://www.cs.utk.edu/ new/rsc3/rsc.htm?calc=res\#mode=adv

Current calculator link:

http://www.ornl.gov/btc/rsc

c) Meeting Notes/Status Update:

The last teleconference was near the holiday break and mostly involved high-level discussion of calculator purpose and functionality. Below are recorded calculator suggestions, changes, and reasons for those changes.

To-Do List:

1. PHP script processing of form data into macro for execution of 2 simulations via engine calls

2. Busy cursor or progress bar (recommended for any process taking longer than 1 or 2 seconds, respectively) during simulation runs

3. Outputs will include: heating and cooling load for summer and winter, dollar annual savings for heating and cooling, and peak demand

4. Output should incorporate building/input conditions

5. Joe Huang working to refine simulation output

6. Scalability analysis - maximum number of concurrent users

7. Mouse-over question mark for helpful definitions or pictures, click for website/ more info 
Internal Changes (discussions between Joshua New, Bill Miller, Joe Huang, and Ender Erdem):

- Semi-permanent link for latest version of the calculator hosted on ORNL servers: http://www.ornl.gov/btc/rsc

- New main/index page and graphics

- Extended cross-compatibility (proper operation by browsers other than Internet Explorer) by using W3C's Validation Service to take the Roof Savings Calculator page from 64 errors and 254 warnings to 6 errors and 0 warnings.

- PHP script was written that takes the posted form data and writes them back to the user with the beginnings of an animated gif progress bar

- Residential and Commercial calculators renumbered with A\# for advanced questions but otherwise dynamic and consistent as the user would expect

- Simple and Advanced mode options at top fully operational

- Collapsible subsections (comparisons collapse together)

- Labels (and not just radio buttons) are clickable

- Indented sections introduced for additional relevant details

- Residential/Commercial title displayed at top is dynamic to let the user know which version they're using

- Drop-down for building type allows easy switching between the Residential and Commercial versions of the calculator

- “Other” radio buttons sometimes only available in advanced mode and clicking makes visible the corresponding text box with cursor ready for typing

- Cascading Style Sheets, CSS-based "look-and-feel” of the website, are adjustable based upon jQuery UI's ThemeRoller. The curious or artistically minded should feel free to play at the web link above and send me your downloaded theme as an option for the appearance of the Roof Savings Calculator.

- Several calculator defaults set according to values used in:

- Akbari and Konopacki, 2005. Calculating energy-saving potentials of heat-island reduction strategies. Energy Policy (33), pp. 721-756, tables 13.

- Levinson and Akbari. 2009. Potential benefits of cool roofs on commercial buildings: conserving energy, saving money, and reducing emission of greenhouse gases and air pollutants. Energy Efficiency, DOI 10.1007/s12053-008-9038-2.

Meeting Info:

- Marc LaFrance recommended: 
- Meeting the last full week of each month (January moved to week before the ASHRAE conference)

- Marc LaFrance recommended alpha release:

- Planned alpha-release as soon as the front-end is integrated with the simulation engine and back-end display of simulation results; however, the current front-end (http://www.ornl.gov/btc/rsc) can be shared with colleagues with feedback directed to Joshua New (newjr@ornl.gov).

General:

3. Conditioned area $\left(\mathrm{ft}^{2}\right)$ :

- Default to 2025 as the average square foot of homes built between 1973 and 2008 (link next to RSC question \#3)

4. Number of floors:

- Joe Huang recommended:

- 2 floors default for residential (currently 1)

A1. Window-to-wall ratio:

- Joe Huang recommended

- 14.5 for residential, 40.0 for commercial

- Window-to-wall differences for office, warehouse, and box store differences

- Units? (window-to-wall [currently] or window-to-sq ft conditioned area)

5. Building Stock:

- Ronnen Levinson recommended

- "Building Stock" -> "Year of construction"

A2. Internal load and A3. Days of Operation per week:

- Joe Huang proposed:

- Removing “A2. Internal load” and “A3. Days of Operation” due to assumed schedules

- Schedule/usage profiles a Phase II initiative

6. Type of heating:

- Ronnen Levinson recommended:

- Renaming to "Heating equipment"

- Renaming options to "natural gas furnace" and "oil furnace”

6.P2. Gas price (cents per therm):

- Ronnen Levinson suggested

- Renaming to "natural gas price"

- Renaming options to dollars instead of USD 
7-8-8. Heating and Cooling system efficiency (HSPF, AFUE, SEER):

- Ronnen Levinson suggested

- AFUE for furnaces, HSPF for heat pump

- Spelling out AFUE/HSPF/SEER acronyms (links added next to question for spelling out acronym in tooltip and link to webpage with more info)

- Answers not parallel/similarly-phrased: changed from advanced, mid-, standard, pre-1992 to high-, mid-, and low-efficiency

- SEER low- (10) and mid-efficiency (13) based upon EERE page and DOE press release

- SEER high-efficiency changed to 15 based upon qualification for the US EPA Energy Star label

Attic/Plenum/Roof:

- Attic/plenum/roof sections reordered working from outside of the building inward

- Default comparison Residential: 20\% asphalt to 50\% reflective metal roof; Commercial: $20 \%$ bitumen to $50 \%$ reflective TPO/PVC

9/19. Roof Type:

- Ronnen Levinson recommended:

- "cool roof membranes (TPO/PVC)" -> "single-ply membrane"

- "pavers (concrete) -> "concrete paver"

- "bitumen (asphalt)" -> "modified bitumen"

• "Built-up Roof" -> "built up"

10/20. Solar reflectance:

- Ronnen Levinson recommended:

- "solar reflectance" -> "aged solar reflectance"

- Changed to Solar reflectance (aged 3 years)

- Tooltip to convert from manufacturer's initial number to an aged number; based on experiments at ORNL's ESRA facility

- Defaults for solar reflectance based on type

- Reduction in number of options

- Other boxes only visible in Adv mode

11/21. Thermal emittance:

- Ronnen Levinson recommended:

- "thermal emittance" -> "aged thermal emittance"

- Changed to Thermal emittance (aged 3 years)

- Tooltip to convert from manufacturer's initial number to an aged number; based on experiments at ORNL's ESRA facility

- Default values of:

0.15 (acrylic-coated galvalume steel)

0.20 (bare galvalume steel) 
0.50 (metallic field-applied coating)

0.85 (painted steel)

0.90 (anything else)

- Changed to the following (to avoid endorsing specific vendor products):

Acrylic Al-Zn coated steel (15\%)

Bare Al-Zn coated steel (20\%)

Metallic field-applied coating (50\%)

Painted steel (85\%)

Standard materials (90\%)

- Other boxes only visible in Adv mode

13/23. Pitch (rise:run):

- Ronnen Levinson recommended:

- "inclination (rise:run)" -> "pitch"

- $\quad$ "steep slope (>8:12)" -> "high (slope > 8:12)"

- $\quad$ "conventional slope (4:12-8:12) " -> "medium (2:12 < slope <= 8:12)"

- $\quad$ "low slope (2:12-4:12)" -> "low (slope $<=2: 12$ )

- delete "flat roof"

- Different defaults/nomenclature for residential vs commercial

14/24. Radiant barrier:

- Ronnen Levinson recommended:

- Renaming to "Radiant barrier present:"

15/25. Level of insulation:

- Ronnen Levinson asks:

- Is this the thermal resistance of the roof assembly, or the thermal resistance of insulation in the roof assembly? Rename "level of insulation" -> "thermal resistance"

- Renamed to "Attic insulation"

- Reduction in number of insulation options

- Other boxes only visible in Adv mode

16/26. Duct location:

- Moved to Attic section as potential option in deep retrofit

17/27. Duct leakage:

- Other boxes only visible in Adv mode

Phase II Initiatives:

○ Options for more building types

- Support for zip code or map location for location selection

○ Support for internal temperatures (for $3^{\text {rd }}$ world countries)

○ Ductwork above the roof plane

○ Options for ballast roof (porous media not modeled by AtticSim) 
○ Other pricing models (such as on-peak and off-peak pricing)

- Cost-effectiveness analysis for optimum return-on-investment

- Schedule/usage profiles a Phase II initiative 